\title{
DEVELOPMENT OF MATERIAL OPTIMIZATION TECHNOLOGY FOR INNOVATION
}

\author{
IKUO TANABE \& PAULO DA SILVA \\ Department of Mechanical Engineering, Nagaoka University of Technology, Japan
}

\begin{abstract}
In recent years, the demand for products of high quality, with hybrid properties, multifunctional, low cost and which is environmentally-friendly has been rapidly increasing. Here, several optimization technologies are currently being used to address these issues. Particularly, topology optimization technology is considered useful in the manufacturing field due to the high quality, high reliability and safety that it offers. However, it has been observed that there is a lack of proper material optimization techniques in the technology development process. There are hundreds of materials used in the industrial field but, surprisingly, there is a minimal amount of research regarding material property optimization for innovative developments. Thus, the present research, through a previously developed software, defined a material optimization technology for innovation. This technology relied on a software that creates new materials with hybrid properties, a hybrid materials manufacturing method, and an algorithm for material optimization. The material optimization technology was then evaluated. It is concluded from the results that: (1) the expanded proposed software was suitable for calculating the Young's modulus, density, coefficient of linear expansion, specific heat and thermal conductivity for several properties; and (2) the material optimization technology was effective for the development of innovative products with defined functions or properties.
\end{abstract}

Keywords: material optimization, new material, hybrid property, three-dimensional and functionally gradient material.

\section{INTRODUCTION}

In the 21st century, the demand for products with high quality [1], hybrid properties [2], multifunctionality [3], low cost and considerable environmental-friendliness [4] has been rapidly increasing. Here, several optimization technologies are currently being used to address these issues. Particularly, topology optimization technology is considered as useful in the manufacturing field due to the high quality, high reliability and safety that it offers. However, it has been observed that there is a lack of proper material optimization techniques in the technology development process. There are hundreds of materials used in the industrial field but, surprisingly, there is a minimal amount of research regarding material property optimization for innovative developments.

Thus, the present research, through a previously developed software, defined a material optimization technology for innovation. This technology relied on a software that creates new materials with hybrid properties, a hybrid materials manufacturing method, and an algorithm for material optimization. The aforementioned software can effectively calculate up to five desired material properties that requested at once (i.e. Young's modulus, density, coefficient of linear expansion, specific heat and thermal conductivity). In addition, the algorithm for material optimization was defined through FEM inverse analysis. The material optimization technology was then evaluated with a simple experiment. In this regard, it was thought that material optimization technologies were highly relevant to explore due to the design and manufacturing implications of having a customized material. 


\section{PROPERTIES CALCULATION MODELS FOR NEW COMPOSITE MATERIALS}

In this section a review of a previously developed software and the equations used in it is presented and explained [5]. For this, the following suffixes refer to the following: "s" stands for fine aggregate, "g" for rough aggregate, "e" for bond (e.g. epoxy resin), "a" for air and "c" for concrete or mortar; " $t$ " for continuous layer and "d" for non-continuous layer.

The following model-describing equations [5] were meant for the calculation of the Young's modulus, density, coefficient of linear expansion and specific heat. In the case of thermal conductivity calculations, the Russell model was used [6]. Every material combination in the developed software for this specific case was constrained to be concrete, porous material and sintered compact. Here, the volume percentage was firstly obtained through eqn (1)

$$
\left.\begin{array}{l}
V \mathrm{~s}=W \mathrm{~s} \cdot \rho_{\mathrm{c}} / \rho_{\mathrm{s}} \\
V \mathrm{~g}=W \mathrm{~g} \cdot \rho_{\mathrm{c}} / \rho_{\mathrm{g}} \\
V \mathrm{e}=W \mathrm{e} \cdot \rho_{\mathrm{c}} / \rho_{\mathrm{e}} \\
V \mathrm{a}=100-(V \mathrm{~s}+V \mathrm{~g}+V \mathrm{e}
\end{array}\right\}
$$

where $V$ was volume percentage (\%), $W$ was weight percentage (\%), $\rho$ was density $\left(\mathrm{kg} / \mathrm{m}^{3}\right)$, and in the case of the porous material or the sintered compact $(W e=0)$, values of $\mathrm{Ve}=\mathrm{We}=10^{-6}$ were used for regular calculation .

As mentioned, the thermal conductivity calculation was done through the Russell model [6] and shown in eqn (2)

$$
\lambda \mathrm{c}=\lambda \mathrm{t} \frac{K \cdot V_{\mathrm{d}}^{2 / 3}+\left(1-V_{\mathrm{d}}{ }^{2 / 3}\right)}{K \cdot\left(V_{\mathrm{d}}{ }^{2 / 3}-V_{\mathrm{d}}\right)+\left(1-V_{\mathrm{d}}{ }^{2 / 3}+V_{\mathrm{d}}\right)}
$$

where $\lambda$ was thermal conductivity $[\mathrm{W} /(\mathrm{m} / \mathrm{K})]$ and $K$ was $\lambda \mathrm{d} / \lambda \mathrm{c}$.

In Fig. 1, the calculation models meant for concrete or composite materials are depicted. First, the thermal conductivity calculation for mortar 1 was done (i.e. when the continuous layer was a bonding material and the non-continuous layer was fine aggregate). Subsequently, the second thermal conductivity calculation meant for mortar 2 was done (i.e. when the continuous layer was the mortar 1 and the non-continuous layer was a middle aggregate). Accordingly, the final thermal conductivity calculation was done in the case in which the continuous layer was mortar 2 and the non-continuous layer was a coarse aggregate. For porous or sintered compact materials $(\mathrm{We}=0)$, values of $\mathrm{Ve}=W \mathrm{e}=10^{-6}$ were utilized.
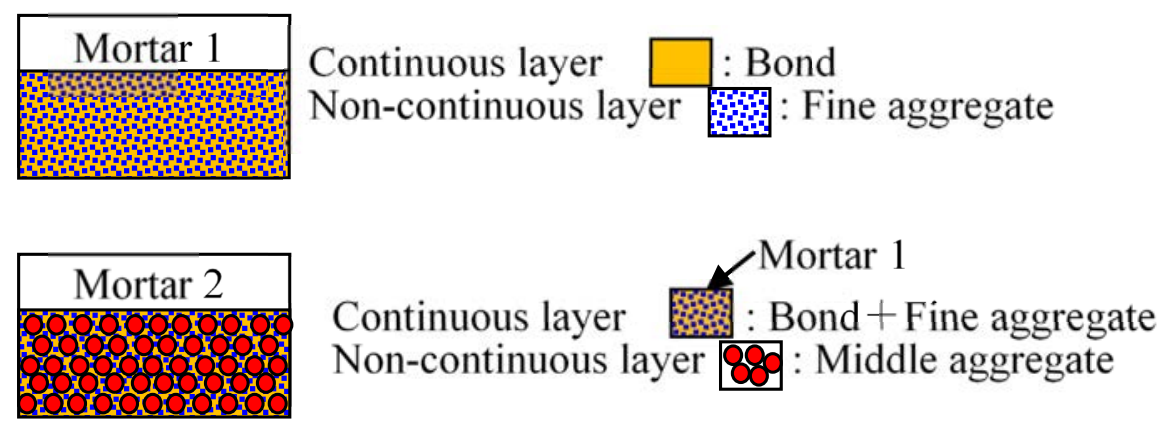

Figure 1: Models for calculation of thermal conductivity. 
In addition, the specific heat calculation was done through eqn (3) [5], [7].

$$
C_{\mathrm{c}}=[\mathrm{Ws} \cdot C \mathrm{~s}+\mathrm{Wg} \cdot \mathrm{Cg}+W \mathrm{We} \cdot \mathrm{Ce}+\{(100-(W \mathrm{~s}+W \mathrm{~g}+W \mathrm{e})\} C \mathrm{Ca}] / 100,
$$

where $C$ was specific heat $[\mathrm{kJ} /(\mathrm{kgK})]$ and $W$ was weight percentage [\%]. For porous or sintered compact materials $(\mathrm{We}=0)$, values of $\mathrm{Ve}=W \mathrm{e}=10^{-6}$ were utilized.

Moreover, the coefficient of linear expansion calculation was done through eqn (4)

$$
\alpha_{\mathrm{c}}=\frac{\alpha_{\mathrm{d}} \cdot V_{\mathrm{d}}+\alpha_{\mathrm{t}}\left\{1+(Y-1)^{+} V_{\mathrm{d}}^{1 / 3}-Y \cdot V_{\mathrm{d}}\right\}}{1+(Y-1)\left(V_{\mathrm{d}}^{1 / 3}-V_{\mathrm{d}}\right)}
$$

where $\alpha$ was linear expansion coeff. [1/K], $Y$ was $E_{\mathrm{t}} / E_{\mathrm{d}}$ and $E$ was Young's modulus (GPa).

Furthermore, the linear expansion coefficient calculations were started with calculations for mortar 1 (i.e. when the continuous layer was a bonding material and the non-continuous layer was fine aggregate). Then, the calculations meant for mortar 2 were done (i.e. when the continuous layer was the mortar 1 and the non-continuous layer was a middle aggregate). Accordingly, the final calculation was done in the case in which the continuous layer was mortar 2 and the non-continuous layer was a coarse aggregate. For porous or sintered compact materials $(\mathrm{We}=0)$, values of $\mathrm{Ve}=W \mathrm{e}=10^{-6}$ were utilized.

Additionally, the Young's modulus calculation was done through eqn (5)

$$
E_{\mathrm{c}}=E_{\mathrm{t}}\left\{1+\frac{V_{\mathrm{d}}}{E_{\mathrm{d}} /\left(E_{\mathrm{d}}-E_{\mathrm{t}}\right)-V_{\mathrm{d}}^{1 / 3}}\right\}
$$

where $E$ was the Young's modulus (GPa). In this regard, the Young's modulus calculations began with calculations for mortar 1 (i.e. when the continuous layer was a bonding material and the non-continuous layer was fine aggregate). After this, the calculations meant for mortar 2 were done (i.e. when the continuous layer was the mortar 1 and the non-continuous layer was a middle aggregate). Finally, calculations for the case in which the continuous layer was mortar 2 and the non-continuous layer was a coarse aggregate. For porous or sintered compact materials $(W e=0)$, values of $V e=W e=10^{-6}$ were utilized. Consistently, the above equations were then considered as the basis for the following chapters and this research.

\section{PROPOSED MANUFACTURING PROCESS FOR THE DESIGNED MATERIALS}

In a similar way, previous researches defined the proposed manufacturing method for the designed materials using the aforementioned equations inside a software (which defined two scenarios: (1) Selecting materials and calculating appropiate ratios to achieve intended effects; (2) Calculating the properties generated with these ratios and materials, and said method was also applied in this research. Consequently, a review of the process was demed as appropiate. For the aforementioned software, a solid body uniformity was assumed for each calculation model but conventional manufacturing of concrete or composites (mixing) yields an heterogeneous mix which in result would be considered as a material defect. Thus, the proposed manufacturing process was meant to achieve high quality by avoiding this issue. The manufacturing procedure is shown in Fig. 2 [8], [9]. Here, a coarse aggregate was firstly put into a mold and filled up to about $60 \mathrm{vl}$ \%. Subsequently, a middle aggregate was poured over the coarse aggregate. After this, hydraulic pressure and vibration were applied over the aggregates to homogenize the mixture. For this, the size of the middle aggregate was resticted to be less than one seventh of the coarse aggregate. Here, the available air given space for the middle aggregate was about $40 \mathrm{vl} \%$ relative to the coarse aggregate. Thus, given that the middle aggregate filled up about $60 \mathrm{vl} . \%$ of the total space, 40 vl.\% would mean that the 


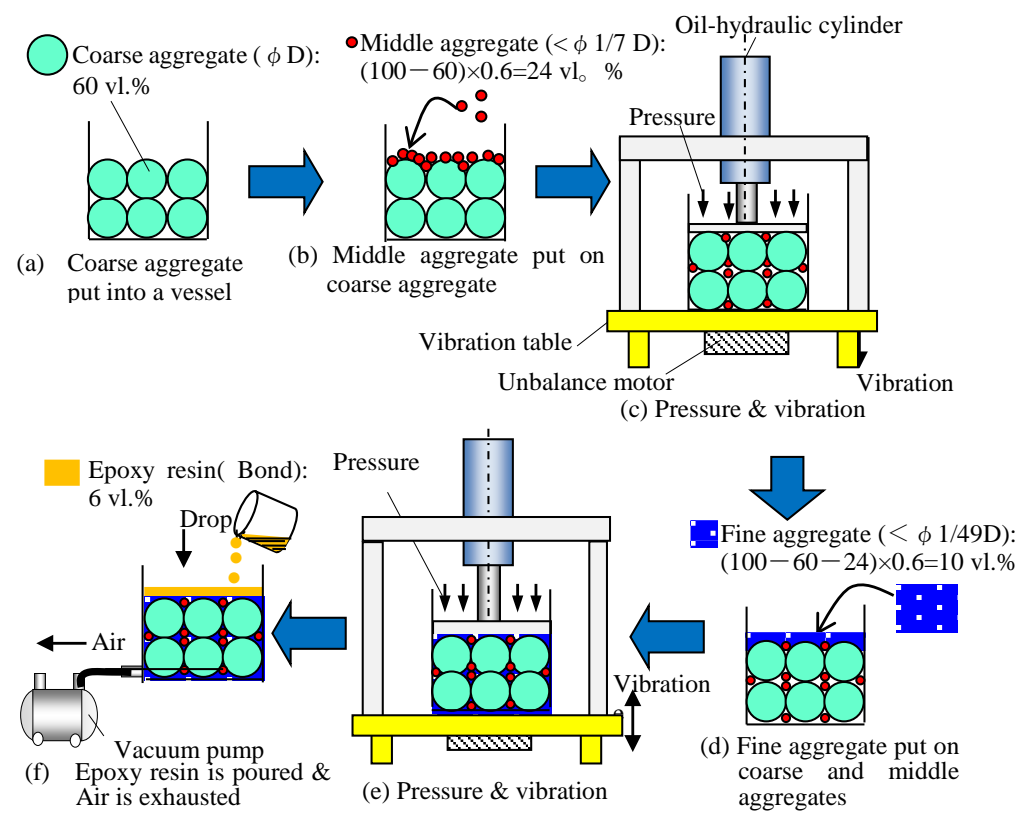

Figure 2: Manufacturing procedure for the composite with hybrid properties.

aggregate filled about 24 vl.\% $(=0.4 \times 0.6)$. Consequently, the coarse and the middle aggregates uniformly filled up $84 \mathrm{vl} . \%$ (=60 vl.\%+24 vl.\%). In addition, fine aggregate was also poured into the mix to fill the gaps between the middle aggregates. It was thought that this aggregate would have filled up to $10 \mathrm{vl} . \%(=(100-60-24) \times 0.6)$. As a result, all aggregates uniformly filled around $94 \mathrm{vl} . \%$ (=60 vl.\%+24 vl.\%+10 vl.\%). It must be considered that space was meant to be filled by the aggregates in a rhombic display and, thus, the mixture becomes a mortar structure. Bonding materials (e.g. epoxy resin) were meant to be poured from upper surface over all aggregates, and the air between the aggregates was taken out from the mixture with a vacuum pump located at the bottom of the shown setup. Upon solidification of the bonding materials, the generated composite material was removed from the mold. Here, the component distribution was similar to that of the calculation model.

The calculation accuracy of the material optimization software was evaluated in the mentioned previous researches. The calculations for density, linear expansion coefficient and specific heat were accurate to around $\pm 5 \%$ but the Young's modulus and thermal conductivity were around $\pm 20 \%$. This was thought to be because of air formation in the composite material and the FEM simulations were modified accordingly; as a result, the software calculation accuracy for the Young's modulus and thermal conductivity reached down to a $\pm 5 \%$ each. This software was then evaluated in several cases with the generation of new composites with hybrid properties [9]-[12].

\section{APPLYING THREE-DIMENSIONAL FUNCTIONAL GRADIENT MATERIALS}

As an addition to the aforementioned designed materials, considerations regarding a threedimensional and functionally gradient material, previously developed using the proposed software as an exercise to devise future innovative materials, were thought to be appropriate [12]. The devised manufacturing procedure for this is shown in Fig. 3. The three-dimensional 


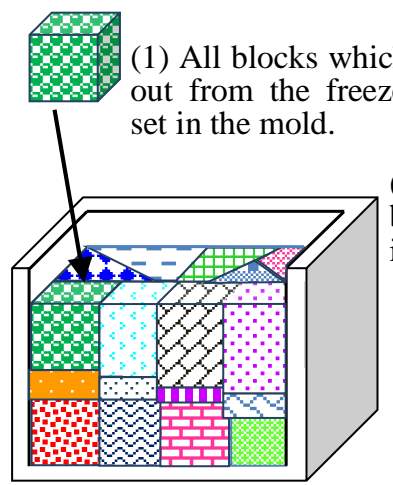

(2) Water in the all blocks are evaporated in an oven.

(3) Epoxy resin is poured in the all blocks using Fig. 2(f).

Figure 3: Manufacturing procedure for a three-dimensional and functionally gradient material.

and functionally gradient material was a very complex structure, as each block had several hybrid properties and were arranged in the directions of the $\mathrm{X}, \mathrm{Y}$ and $\mathrm{Z}$ axes. Said hybrid properties were calculated by using the developed software and each block was manufactured using the procedure shown in Fig. 2. However, tap water was utilized in exchange for the bonding material (i.e. epoxy resin) shown in Fig. 2. Here, the blocks were frozen and kept in a freezer. After that, all the blocks were taken out of the freezer and put into a mold, then the frozen tap water in all the blocks was evaporated in an oven. Next, the epoxy resin was poured in exchange for the frozen tap water over all the blocks using Fig. 2(f). The manufactured three-dimensional and functionally gradient material is shown in Fig. 4. Here, the structure was deemed to be unique in the material optimization field.

\section{MATERIAL OPTIMIZATION ALGORITHM USING FEM INVERSE ANALYSIS} Nowadays, designers in the manufacturing field rely on computer simulations and CAE systems. Commonly, the input data was the original design, its shape and size, the boundary conditions and several material properties. Here, designers are constrained to the currently available material databases. However, as current technology trends demand ever-increasing

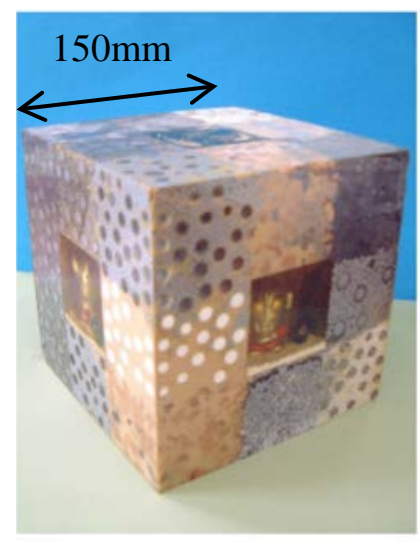

Figure 4: Photograph of a three-dimensional and functionally gradient material. 
performances, the need for new materials with improved characteristics is of concern. Therefore, the material optimization technology presented in this paper and in the following chapter consisted in a vertical integration of the previously developed material optimization software, the previously explored manufacturing process and the FEM inverse analysis tools that are explained in this chapter; this was thought to then offer the designers a wider material set of options and improve the quality and performance of their designs.

In this section, an algorithm for material optimization using inverse analysis of the FEM was developed as depicted in Fig. 5. First, the input would be the defined desired functions of the material based on the demanded product characteristics (which could be influenced by marketing data). The most suitable properties to satisfy the desired functions on the innovative product were calculated by both the inverse analysis of the FEM simulation and the method of successive substitution in a personal computer. Here, the FEM simulations were static analysis, thermal analysis and vibration analysis and outlined in Table 1; this table also shows the relationship between the different simulations features and the necessary properties for each analysis. The necessary materials and its composite ratio for the new materials exhibiting the most suitable properties, calculated through the algorithm, were then calculated by the previously developed software [13]. Then the new composite material with the most suitable properties was manufactured using the procedure shown in Section 3. In addition, the innovative product could have the various property distributions by using the three-dimensional functional gradient material manufacturing method shown in Section 4.

\section{EVALUATION FOR THE MATERIAL OPTIMIZATION TECHNOLOGY}

The evaluation of the proposed material optimization technology is covered in this section. The relationship between the desired characteristics and the calculated properties using the algorithm of the material optimization is shown in Table 2. Here, a block with length $60 \mathrm{~mm} \times$ width $45 \mathrm{~mm} \times$ height $75 \mathrm{~mm}$ was used for the evaluation under two different analyses. The desired block performances (input) were: when the load on the upper surface of the block is $1000 \mathrm{~N}$, the displacement in the vertical direction becomes $-3.2 \mu \mathrm{m}$; and resonance

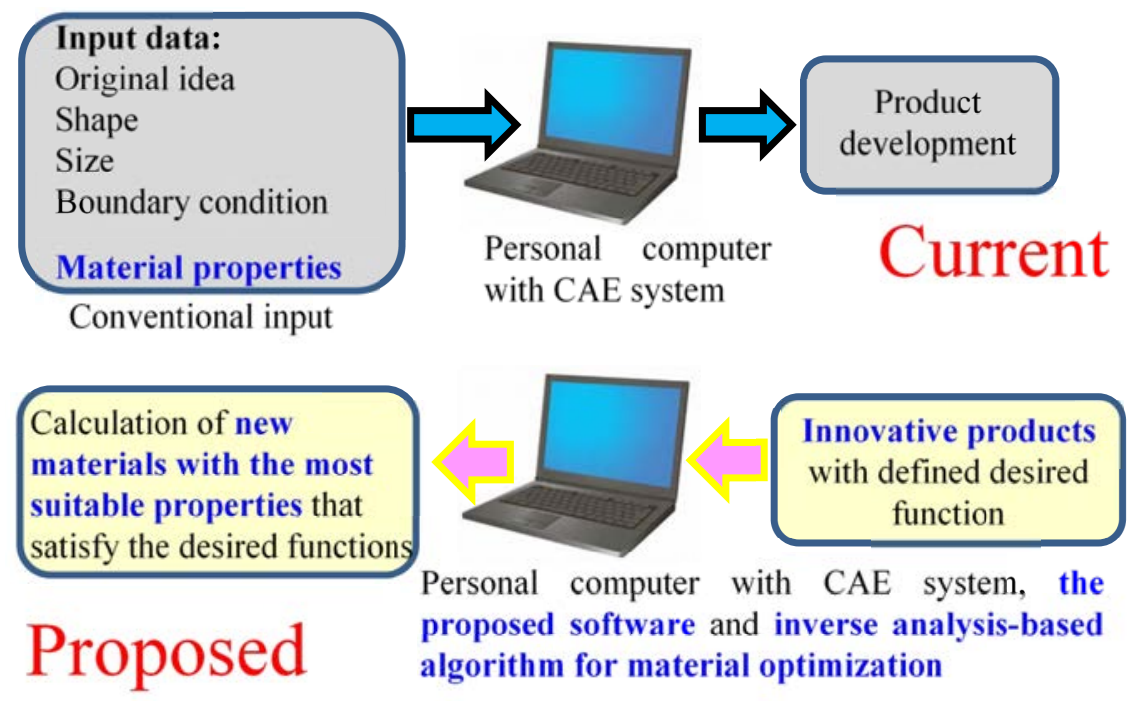

Figure 5: Innovative development using the proposed software and the algorithm for material optimization using FEM inverse analysis. 
Table 1: Several properties used for the input data in certain FEM simulations.

\begin{tabular}{|l|l|l|l|}
\hline \multicolumn{2}{|l|}{ Kinds of FEM simulation } & Boundary conditions & Input data for FEM \\
\hline Static analysis & Fix condition & $\begin{array}{l}\text { Shape \& Size } \\
\text { Material properties (Young's } \\
\text { modulus \& Poisson's ratio) }\end{array}$ \\
\hline $\begin{array}{l}\text { Thermal } \\
\text { analysis }\end{array}$ & Steady state & $\begin{array}{l}\text { Heat transfer } \\
\text { coefficient }\end{array}$ & $\begin{array}{l}\text { Shape \& Size } \\
\text { Material properties (Thermal } \\
\text { conductivity) }\end{array}$ \\
\cline { 2 - 4 } & Non-steady state & $\begin{array}{l}\text { Heat transfer } \\
\text { coefficient }\end{array}$ & $\begin{array}{l}\text { Shape \& Size } \\
\text { Material properties(Density, } \\
\text { specific heat and thermal } \\
\text { conductivity) }\end{array}$ \\
\hline $\begin{array}{l}\text { Vibration } \\
\text { analysis }\end{array}$ & Free vibration & Fix condition & $\begin{array}{l}\text { Shape \& Size } \\
\text { Material properties(Young's } \\
\text { modulus \& density) }\end{array}$ \\
\cline { 2 - 4 } & Forced vibration & $\begin{array}{l}\text { Fix condition and } \\
\text { damping ratio }\end{array}$ & $\begin{array}{l}\text { Shape \& Size } \\
\text { Material properties(Young's } \\
\text { modulus \& density) }\end{array}$ \\
\hline
\end{tabular}

Note: At thermal deformation analysis, both Static and Thermal analysis are used, and coefficient of linear expansion is also used for input data. Poisson's ratio is always 0.3.

Table 2: Relationship between the desired characteristics and the calculated properties using the algorithm of the material optimization.

\begin{tabular}{|c|c|}
\hline \multirow{2}{*}{$\begin{array}{l}\text { The desired characteristics for the } \\
\text { block with } 60 \mathrm{~mm} \times 45 \mathrm{~mm} \times 75 \mathrm{~mm} \text {. }\end{array}$} & $\begin{array}{l}\text { The displacement in the height direction } \\
\text { become }-3.2 \mu \mathrm{m} \text { at } 1000 \mathrm{~N} \text { load. }\end{array}$ \\
\hline & $\begin{array}{l}\text { The resonance frequencies of the first and } \\
\text { the second models are } 5200 \mathrm{~Hz} \text { and } 6100 \mathrm{~Hz} \\
\text { respectively. }\end{array}$ \\
\hline \multicolumn{2}{|c|}{$\begin{array}{l}\text { The FEM models for the inve } \\
\text { Upper surface: } 1000 \mathrm{~N} \\
\begin{array}{l}\text { Nodes: } 10141 \\
\text { Elements: } 6664\end{array}\end{array}$} \\
\hline The calculated properties & $\begin{array}{l}\text { Density: } 4183 \mathrm{~kg} / \mathrm{m}^{3} \\
\text { Young’s modulus: } 79.3 \mathrm{GPa}\end{array}$ \\
\hline
\end{tabular}




\begin{tabular}{|l|l|l|}
\hline \multirow{2}{*}{} & \multicolumn{2}{|c|}{ Specifications of the block } \\
\cline { 2 - 3 } & Size & $60 \mathrm{~mm} \times 45 \mathrm{~mm} \times 75 \mathrm{~mm}$ \\
\cline { 2 - 3 } & Coarse aggregate & Aluminum $\left(121500 \mathrm{~mm}^{3}, 328 \mathrm{~g}\right)$ \\
\cline { 2 - 3 } & Middle aggregate & Zinc $\left(48600 \mathrm{~mm}^{3}, 347 \mathrm{~g}\right)$ \\
\cline { 2 - 3 } & Fine aggregate & Steel $\left(20250 \mathrm{~mm}^{3}, 159 \mathrm{~g}\right)$ \\
\cline { 2 - 3 } & Bond & Epoxy resin $\left(12150 \mathrm{~mm}^{3}, 14.6 \mathrm{~g}\right)$ \\
\cline { 2 - 2 } & $\begin{array}{l}\text { When the load on upper surface of the block is } 1000 \mathrm{~N}, \\
\text { the displacement in the height direction become }-3.3 \mu \mathrm{m}, \\
\text { and the resonance frequencies of the first and the second } \\
\text { models are 5208 Hz and 6100 Hz respectively. }\end{array}$ \\
\hline
\end{tabular}

Note: Volume $\mathrm{mm}^{3}$,weight g.

Figure 6: Photograph of the new composite material using the material optimization technology and its specifications.

frequencies were thought to be $5200 \mathrm{~Hz}$ and $6100 \mathrm{~Hz}$ respectively. The necessary properties for achieving the desired characteristics of the block were firstly calculated by the algorithm of the material optimization using inverse analysis of the FEM. The FEMs simulations used were a static and a free vibration analyses. Here, the necessary properties for achieving the desired characteristics of the block were the Young's modulus and density, which were simultaneously considered.

Then the several component materials and the weight percentages for the new composite material with the desired properties were calculated by the developed original software. The calculated results are shown in Table 3 . The coarse, middle, fine aggregates and bonding material are aluminum, zinc, steel and epoxy resin, respectively. The weight percentages (volume percentages) were 38.7\% (60 vl.\%), 40.9\% (24 vl.\%), 18.7\% (10 vl.\%) and 1.7\% (6 vl.\%) respectively. The characteristics, behavior and the properties of the manufactured blocks with the new composite material were experimentally measured and the results are shown in Table 4. For this the following was considered, when the load on the upper surface of the block is $1000 \mathrm{~N}$, the displacement in the height direction was measured by using a

Table 3: The calculated three aggregates and one bond for the new composite material with the optimized properties and these weight percentages.

\begin{tabular}{|l|c|c|c|c|}
\hline Components & \multicolumn{3}{|c|}{ Aggregates } & \multirow{2}{*}{ Bond } \\
\hline Classification & Coarse & Middle & Fine & - \\
\hline Size & $\phi 10 \mathrm{~mm}$ & $\phi 1.0 \mathrm{~mm}$ & $\phi 0.1 \mathrm{~mm}$ & Epm \\
\hline Material & Aluminium & Zinc & Steel & Epoxy resin \\
\hline Density & $2700 \mathrm{~kg} / \mathrm{m}^{3}$ & $7130 \mathrm{~kg} / \mathrm{m}^{3}$ & $7830 \mathrm{~kg} / \mathrm{m}^{3}$ & $1200 \mathrm{~kg} / \mathrm{m}^{3}$ \\
\hline $\begin{array}{l}\text { Young's } \\
\text { modulus }\end{array}$ & $69 \mathrm{GPa}$ & $96.5 \mathrm{GPa}$ & $205 \mathrm{GPa}$ & $2.6 \mathrm{GPa}$ \\
\hline $\begin{array}{l}\text { Weight } \\
\text { (weight \%) }\end{array}$ & $\begin{array}{c}328 \mathrm{~g} \\
(38.7 \%)\end{array}$ & $\begin{array}{c}347 \mathrm{~g} \\
(40.9 \%)\end{array}$ & $\begin{array}{c}159 \mathrm{~g} \\
(18.7 \%)\end{array}$ & $\begin{array}{c}14.6 \mathrm{~g} \\
(1.7 \%)\end{array}$ \\
\hline $\begin{array}{l}\text { Volume } \\
\text { (volume \%) }\end{array}$ & $\begin{array}{c}121,500 \mathrm{~mm}^{3} \\
(60 \%)\end{array}$ & $\begin{array}{c}48,600 \mathrm{~mm}^{3} \\
(24 \%)\end{array}$ & $\begin{array}{c}20,250 \mathrm{~mm}^{3} \\
(10 \%)\end{array}$ & $\begin{array}{c}12,150 \mathrm{~mm}^{3} \\
(6 \%)\end{array}$ \\
\hline
\end{tabular}

Note: The block is with length $60 \mathrm{~mm} \times$ width $45 \mathrm{~mm} \times$ height $75 \mathrm{~mm}$. 
Table 4: Evaluation: the characteristics, behaviour and the properties in the manufactured block with the new composite material.

\begin{tabular}{|l|c|c|}
\hline Desired characteristics & $\begin{array}{c}\text { Experimental } \\
\text { values }\end{array}$ & Error $\%$ \\
\hline The displacement: $-3.2 \mu \mathrm{m}$ at $1000 \mathrm{~N}$ & $-3.5 \mu \mathrm{m}$ & $9.4 \%$ \\
\hline The first resonance frequencies:5200 Hz & $5130 \mathrm{~Hz}$ & $1.3 \%$ \\
\hline The first resonance frequencies:6120 Hz & $6053 \mathrm{~Hz}$ & $1.3 \%$ \\
\hline
\end{tabular}

Note: Error $=\mid$ Experimental values - Desired characteristic $|\div|$ Desired characteristic $\mid \times 100$.

compression tester, and the Young's modulus was calculated by using this data. Additionally, the resonance frequencies of the first and the second models of the manufactured block were measured by the frequency response method using an impact hummer, an acceleration pickup and a FFT. Here, it can be said that the manufactured block has the desired characteristics demanded initially and valuable as an innovation source. This technology was deemed as effective for the design and manufacture of innovative products.

\section{CONCLUSION}

It is concluded from the results that:

(1) As presented before, the expanded proposed software was able to calculate Young's modulus, density, coefficient of linear expansion, specific heat and thermal conductivity for several properties.

(2) The material optimization technology was effective for the development of innovative products with defined desired functions or properties. This was achieved through a vertical integration of the previously developed material optimization software, the previously explored manufacturing process and the FEM inverse analysis tools suggested in this research.

\section{REFERENCES}

[1] Moriwaki, T., Shamoto, E. \& Tokunaga, T., Thermal deformation of an ultra-precision machine tool due to environmental temperature change. Transactions of the Japan Society of Mechanical Engineers, Series C, 63(615), pp. 4025-4030, 1997. (In Japanese.)

[2] Nakajima, H., Lotus-type porous metals. Bulletin of The Iron and Steel Institute of Japan, 6(9), pp. 701-707, 2001. (In Japanese.)

[3] Kobayashi, T., Matsubayashi, T. \& Shibata, K., On the improvement of the damping capacity of a steel structure by overlaying with fiber-reinforced plastics. Transactions of the Japan Society of Mechanical Engineers, Series C, 58(554), pp. 3096-3101, 1992. (In Japanese.)

[4] Okada, M., Hosokawa, A., Asakawa, N., Fujita, Y. \& Ueda, T., Influence of minimum quantity lubrication on tool temperature in end milling of difficult-to-cut materials having low thermal conductivity. Transactions of the Japan Society of Mechanical Engineers, Series C, 78(792), pp. 3093-3103, 2012. (In Japanese.)

[5] Tanabe, I., Development of technology for creating composite materials of machine tool. Int. J. of Automation Technology, 9(6), pp. 714-719, 2015.

[6] Russell, H.W., Principles of heat flow in porous insulators. J. Am. Ceram. Society, 18, pp. 1-5, 1956. 
[7] Tanabe, I., Takada, K. \& Nakamura, A., Thermal and mechanical characteristics of epoxy resin concrete used in machine tool structures. Transactions of the Japan Society of Mechanical Engineers, Series C, 56(525), pp. 1314-1321, 1990. (In Japanese.)

[8] Tanabe, I., Mizutani, J. \& Yamada, Y., Development of ceramic resin concrete for precision machine tool structures (development of three-dimensional and functionally gradient material). Transactions of the Japan Society of Mechanical Engineers, Series C, 62(596), pp. 1619-1625, 1996. (In Japanese.)

[9] Tanabe, I., Takiguchi, S. \& Iyama, T., Development of software for creating new materials with hybrid properties. Transactions of the Japan Society of Mechanical Engineers, Series C, 78(786), pp. 595-604, 2012. (In Japanese.)

[10] Tanabe, I., Takada, K. \& Nakamura, A., Thermal and mechanical characteristics of epoxy resin concrete used in machine tool structures. Transactions of the Japan Society of Mechanical Engineers, 56(525), pp. 1314-1321, 1990. (In Japanese.)

[11] Tanabe, I., Mizutani, J. \& Yamaday, Y., Development of ceramic resin concrete for precision machine tool structures (development of three-dimensional and functionally gradient material). Transactions of the Japan Society of Mechanical Engineers, 62(596), pp. 1619-1625, 1996. (In Japanese.)

[12] Tanabe, I., Konndo, T., Yamada, Y. \& Mizutani, J., Development of three-dimensional and functionally gradient material and evaluation of the composite structure lathe using the material. Transactions of the Japan Society of Mechanical Engineers, 64(627), p. 4472, 1998. (In Japanese.)

[13] Tanabe I., Development of software for the creation of new materials with hybrid properties. WIT Transactions on Engineering Sciences, Vol 116, WIT Press: Southampton and Boston, pp. 139-147, 2017. 